\title{
THE APPLICATION OF BIM TECHNOLOGY AND ITS RELIABILITY IN THE STATIC LOAD ANALYSIS
}

\author{
Tatjana Baroš
}

Professional paper

BIM (Building Information Modelling), or modelling based on object data, is a process that involves the construction of virtual objects, i.e. the creation and management of digital representations of physical and functional characteristics of objects. The BIM system, therefore, is used to create a model using relevant information. BIM is applicable throughout the entire life cycle of a building, from the design phase, and is then also applicable in the phases of construction as well as management and maintenance. There are many software packages based on the BIM concept. Those are digital software packages used to create 3D object representations with layers of additional project information. Basically, the BIM system parameters are "intelligent" objects that are not only visual displays, but also contain other information required in the design process and the preparation of project documentation. BIM software allows various kinds of analysis of objects. It has wide application in the theory of structures and static load analysis, because it allows a variety of analyses and 3D simulations as well as a range of calculations and the dimensioning of structural parts.

Keywords: BIM; BIM technology; static load analysis; reliability; virtual information model

Primjena BIM tehnologije i njezina pouzdanost u statičkoj analizi konstrukcija

Stručni članak

BIM (Building InformationModelling) ili modeliranje na osnovu podataka o objektu je proces koji podrazumijeva gradnju objekta virtualno, stvaranje i upravljanje digitalnim prikazima fizikalnih i funkcionalnih karakteristika objekta. U BIM sustavu se kreira model s relevantnim informacijama. BIM je primjenjiv tijekom cijelog životnog ciklusa objekta od faze projektiranja, zatim faze izgradnje objekta do faze upravljanja i održavanja objekta. Danas postoje brojni softveri zasnovani na BIM konceptu koji stvaraju 3D prezentaciju objekta i imaju slojeve s dopunskim projektnim informacijama. U osnovi BIM sustava su parametarski "inteligentni" objekti koji osim vizualnog prikaza u sebi sadrže i druge informacije potrebne kod projektiranja i izrade projektne dokumentacije. BIM koncept kroz svoje softvere omogućava različite analize objekata. Dosta je široka njegova primjena u teoriji konstrukcija i statičkoj analizi objekata, jer omogućava razne analize i 3D simulacije kao i brojne proračune i dimenzioniranje dijelova konstrukcije.

Ključne riječi: BIM; BIM tehnologija; statička analiza konstrukcija; pouzdanost; virtualni informacijski model

\section{Introduction}

BIM (Building Information Modelling), or modelling based on object data, is a process that involves the creation and management of digital representations of physical and functional characteristics of structures. Models obtained on the basis of information about a structure become a common source of information needed to support decision-making from the preliminary stages, to design and construction, through the rest of its life cycle, to its potential demolition.

Building information modelling has been the most significant change in the construction industry since the creation of CAD tools. BIM was developed as a way of managing the entire life cycle of a building, from initial design ideas to using the building. The effectiveness of communication between the contractor and the design team can be improved by using BIM technology. Using BIM technology also ensures a significant reduction in costs and increased general efficiency, from developing $3 \mathrm{D}$ design documents to construction works to effective use, maintenance, renovation and adaptive reuse [1].

Building Information Modelling combines geometry, spatial relations, lighting analysis, geographical parameters, quantity and technical description of elements (for example, details of the manufacturers of individual elements or parts of a building) [2]. BIM can represent the entire life of an object, from the building process to the use scenario, namely, its maintenance. BIM allows easy access to all necessary information about quantities (for example, when doing a cost analysis). Individual elements may be extracted from the project and their variables separately determined. The systems, assembly or parts of an object can be shown to scale in relation to the entire object or group of objects.

This concept allows lower costs, faster construction, higher quality, fewer conflicts and greater satisfaction [3]. The concept of BIM has been around since the 1970s. The term Building Information Model appeared in a paper by G.A. van Nederveen. The phrase Building Information Modelling was coined by Charles M. Eastman, although he originally used a slightly different term, Building Product Model. This term often appears in his published works from the late seventies [2]. In any case, both this term and Building Information Modelling, abbreviated to BIM, only became popular when Autodesk began using the concept [4].

Phillip G. Bernstein, a FAIA architect and industrial strategist, first used the acronym "BIM" for building information modelling. The person to be thanked for popularizing and standardizing it is Jerry Laiserin [2]. Jerry Laiserin helped popularize and standardize the expression as a common name for digital building display, offering a number of names for it. Since the mid1980s, BIM has been commonly used to denote the concept of digital display of the design process, developed and marketed by software companies such as Bentley Systems, Autodesk and Graphisoft [2]. Graphisoft used the term soft 'Virtual Buildings', and Bentley Systems 'Integrated Project Models', in order to facilitate the exchange and interoperability of information in digital form [3, 5]. In January 2014, European architects and other engineers from the AEC sector supported the proposal of the European Parliament to 
modernize the EU public procurement procedure by adopting new principles of work in order to increase competitiveness. In other words, the European Union chose to follow the United Kingdom and its BIS (Department of Business Innovation and Skills).

The BIM strategy requires that by 2016 the BIM technology be exclusively used in the design of all projects resulting from public tenders. The European Union Public Procurement Directive (EUPPD) encourages, specifies and orders the use of BIM solutions by all EU Member States. It is important to note that the Netherlands, Denmark, Finland and Norway have insisted on the use of BIM in all publicly funded projects for a long time [2].

\subsection{Definition}

Wikipedia, the free electronic encyclopedia, gives the following definition: 'In design, the concept of BIM implies that each element of a project includes not only a visual representation of that element, but also information that is essential for the preparation of project documentation.' Thus, BIM is used to create a model with relevant information or database. This information may be dimensions, quantities, types of materials, specifications, positions, manufacturer information, prices, etc. When the user has all the necessary information about the different project elements, producing technical documentation is much faster and more accurate than with any other system [6].

One definition says: 'BIM (Building Information Modelling) is a comprehensive design process that begins by designing the concept of an object, and ends with the production of the project documentation for the facility construction, construction management and maintenance in the exploitation phase.' Building Information Modelling (BIM) is a digital display of the physical and functional characteristics of a structure. BIM is a shared knowledge resource for information about a structure, which forms a sound basis for decision-making during its entire life cycle, defined as existing from the earliest design stage to the structure demolition [7].

Traditional building design is largely based on twodimensional drawings (plans, sections, etc.). BIM extends that beyond the 3D by raising the level of the three basic spatial dimensions (width, height and depth $-X, Y$ and $Z$ ). With the time as the fourth dimension and the price as the fifth dimension, BIM encompasses more than just geometry. It also includes spatial relationships, lighting analysis, geographic information, and quantities and properties of building components (e.g. manufacturer details). For professionals involved in a project, BIM allows the designer team (architects, surveyors, civil engineers, etc.) to deliver a virtual information model to the contractor and subcontractors, as well as to the owner / operator; each expert adds his or her discipline, creating a pool of specialist knowledge applied to a common model. This reduces the loss of information that typically occurs when a new team becomes the new 'owners' of a project, and provides more information to owners of complex structures.

BIM can be used to show the entire cycle of building, support processes, including cost management, construction management, project management and operation of the structure. It is easy to calculate the quantities and common properties of materials. The scope of work can be isolated and defined. Compositions, assemblies and sequences can be shown to scale in relation to the entire structure or a group of structures. Dynamic information about the construction process, such as sensor and control signal readings from the building system, can also be included in BIM to support construction, operation and maintenance analysis.

Modern BIM design tools define objects parametrically. Objects and their relations to other objects are defined in the form of parameters, with changes to one object automatically leading to changes in all the other objects connected to it. Parametric objects are automatically rebuilt in accordance with the rules built into them $[3,7]$.

BIM is actually similar to the concept of PLM (Product Lifecycle Management) because it overcomes the problems of geometry and tackles aspects such as cost management and project management, while also analysing the various ways in which a structure can be used. Hence, transition to BIM is not like replacing one type of software with another. BIM requires a completely different approach to design and far more interactive exchange of data than most architects, engineers and other professionals are used to.

BIM allows modelling individual parts and components of buildings, which is an advantage over conventional programs, which use vector drawings based on the lines that make up drawings. The biggest advantage of BIM is that it allows reliable transfer of information between different project teams, as well as designers and artists [2].

\section{BIM through the life cycle of an object}

The use of BIM, the concept of modelling based on object data, goes beyond planning and designing a project. Equally important is its use during and after the construction phase, as well as during the phase of facility management. Today, the Internet supports cooperation between individuals and companies in processing and exchanging design and building data, as well as in life cycle projects. The U.S. National Institute of Standards and Technology (NIST) defines a computing environment in which communities and structures may be built publicly (maps and files), while still protecting the rights of persons (corporations). A hybrid cloud, according to the NIST, is a technology that manages the digital rights of data users working in it (safety) Models based on object data incorporate the time frame definition concept.

To ensure effective management of information processes throughout this period, a BIM manager may be appointed to manage the project, develop and monitor an object-oriented BIM, support multidisciplinary building information models, water analysis, schedules and logistics. Those participating in the building process are continuously faced with the challenge to successfully deliver the project, despite tight budgets, limited manpower, busy and limited schedules.

The BIM concept allows the virtual construction of a building before its actual physical construction, in order 
to reduce uncertainty, improve safety, solve problems, and perform potential impact simulation and analysis. Contractors from different fields can bring important information to the model before the commencement of construction, with possibilities for prefabrication or assembly of some systems outside the site and terrain. Waste can be reduced on the spot and products delivered on time, to prevent delays in the field. BIM can bridge the information gap associated with the project delivery of the design team to the construction team and the owner/operator, so that each group adds references to the information gained in the process of BIM model development. This can lead to benefits for the facility owner or operator. For example, a building owner may find evidence of a leak in his building.

Rather than exploring the building physically, he can turn it into a model and see if there is a valve at the place of the suspected leak. The model may also contain the valve size, manufacturer, part number and all other information previously explored, as permitted by the available computing power [8,9]. Despite the fact BIM technologies were initially linked to architecture, the principles underlying the development of precise 3D digital models relate to almost all infrastructure projects that require the engagement of surveyors and civil engineers on a daily basis. The BIM system is based on 3D models of objects, which contain a lot of related information in addition to visual displays, e.g. geodetic coordinates, quantities of materials and elements, properties of elements (thermal conductivity, mass or strength), structural elements of buildings, price and a lot of other information necessary for developing project documentation.

BIM allows the creation of as-built models, i.e. models of existing buildings, to be used by engineers and contractors working on reconstruction or conversion. Researchers from all over the world dealing with sustainable development, green building and environmental protection increasingly emphasize the fact that buildings account for $40 \%$ of total energy consumption and annual greenhouse gas emissions and more than $30 \%$ of the total consumption of water resources. Also, the current economic situation has significantly limited new construction and promotes renovation or adaptive reuse projects as highly costeffective.

Experts claim that $60 \%$ of the projects in the next 20 years will use the existing structures. Having accurate data about existing buildings is becoming an essential link in the overall planning process and process creation in spatial planning of this kind. The process of adapting old buildings to new purposes, so-called adaptive reuse, is a kind of shift in the construction industry [1].

\section{BIM standards}

BIM is often associated with the Industry Foundation Classes (IFCS) and aecXML included information. IFCS has developed buildingSMART - intelligent building (formerly the International Alliance for Interoperability), as a neutral, non-proprietary or open standard for exchanging data between different BIM software applications (some proprietary data structures have been developed by manufacturers and included in their BIM CAD software).

Poor interoperability has long been considered an obstacle to efficiency in the industry, and in particular an obstacle to the adoption of BIM. In August 2004, the American National Institute of Standards and Technology (NIST) released a report that conservatively estimated an annual loss of 15,8 billion dollars by the American capital in the buildings industry due to inadequate interoperability stemming from the fragmented nature of the industry [3]. An early example of nationally approved BIM standards is that by the AISC (American Institute of Steel Construction), which approved the CIS/2 standard, a non-proprietary standard originating in the UK.

There have been attempts to create BIM for older, existing facilities. They usually indicate key metrics such as the Facility Condition Index (FCI) [10]. The validity of these models will have to be monitored over time, since there have been attempts to model buildings built, for example, in 1927, which requires a number of assumptions about design standards, building codes, construction methods, materials, etc., and is therefore far more complex than developing a BIM at the time of project commencement.

BIM is a relatively new technology in the industry, typically slow to adopt change. However, many early buyers are convinced that BIM will begin to play a key role in the construction documents. Proponents argue that BIM offers enhanced visualization, enhanced productivity due to easy retrieval of information, enhanced coordination of construction documents, embedding and linking of vital information such as suppliers of certain materials and quantities required for estimation and tendering, increased speed of delivery, and reduced costs $[3,5,7]$.

Green Building XML (gbXML) is the formation of patterns, a subset of the BIM effort directed toward green building and operation. gbXML is used as input in several energy simulation engines. But with the development of modern computer technology, a large number of building energy simulation tools are available on the market. When choosing which simulation tool to use in the project, the user must take into account the accuracy and reliability of the tool with respect to the construction of the information they have on hand, which will serve as input for the tool. Yezioro, Dong and Leite have developed an artificial intelligence approach to the assessment of construction results of simulations and found that more detailed simulation tools have the best simulation performance in terms of heating and cooling and electricity consumption, with the mean absolute error of $3 \%$.

The concept and methods are: 3D BIM, 4D BIM, BIM 5D, 6D BIM, architectural engineering, architecture, BIM Wash, construction management, design engineering computing, integrated project delivery, virtual design and construction, a design guide for the entire building.

\subsection{Software based on the BIM concept}

BIM software for architectural design and construction of buildings has been present in the construction industry for over two decades. In recent years, it took precedence over the traditional CAD 
concept in all leading design offices in the world. It has become unthinkable to do big projects without the use of BIM technology. Besides standard geometric information, BIM contains information about spatial relations, light analysis, geographic parameters, quantity and technical description of elements (for example, details of manufacturers of certain elements of the building) [2].

BIM (Building Information Modelling) is the process of creating and managing project data during the development of the project. In contrast to the conventional CAD concept, BIM goes beyond seeing projects as drawings. Therefore, the transition from ordinary CAD software to BIM is not a simple change of the working environment of one kind but entry into a whole new world of amazing possibilities. The benefits of BIM usually emphasized by its proponents are better visualization, improved productivity due to easy exchange of information, better coordination of project documents, adding and linking key information (specification of materials, positions of details and parameters of the quantities required for ordering and costing), faster design and lower costs.

The original task of the CAD system is actually making simple the process of graphic representation of elements. The initial focus of the application of CAD is the representation of 2D geometry using graphic elements such as lines, knots and symbols. In this context, walls are represented as parallel lines, to give one example. In order to better organize graphic elements, the concept of layers was introduced, which groups elements with the same characteristics. For example, the lines used to demarcate walls are assigned the wall layer. By working in this way it is possible to develop 2D views, upgrade them and export them from CAD environments, but this cannot be used to show other, more complex relations between elements. The emergence of $3 \mathrm{D} \mathrm{CAD}$ environments initially focused almost exclusively on the creation of geometry in favour of visualization, while subsequent progress concentrated on creating photo-realistic perspective views which included lighting effects etc. In recent years, object-oriented CAD systems (OOCAD) have replaced $2 \mathrm{D}$ objects with $3 \mathrm{D}$ objects capable of better showing relations between the common elements of a building. These objects can be displayed in multiple views and have associated non-graphic attributes. With the introduction of parametric 3D geometry, changeable dimensions and assigned rules, objects were made 'intelligent', which allowed the display of complex geometric and functional relations between elements of buildings.

BIM (Building Information Modelling) is the latest generation of OOCAD systems, which allows the combination of all elements of intelligent structures for the purpose of their common existence in a single database of the project or virtual structure, containing all relevant information. The BIM model is theoretically an integrated, logical and comprehensive source of information related to a structure.

BIM is a process that requires considerable experience and knowledge of all stakeholders/ participants in order to avoid application problems. The BIM technology is supported by the fact that it is slowly becoming standard, with more investors not only requiring but insisting on working in the BIM environment [1].

A range of software based on the BIM concept is available: ArchiCAD from Graphisoft, MicroStation from Bentley Systems, Revit from Autodesk, TeklaBIMsight from Tekla Corporation, VectorWorks and Allplan from Nemetschek, Bocad from Aveva [1].BIMis digital software that creates $3 \mathrm{D}$ representations of objects with layers of additional project information. This is sometimes referred to as the $5 \mathrm{D}$ representation of structures, where the 4th and 5th dimensions are the time and cost. For example, using BIM an architect can simulate how wind blows around and through a building and how the ventilation and wind speed may change if you change the shape or size of the building materials. Additional information that can be modelled in BIM includes details of components and specifications, materials, structural loads, air flow, water flow, spatial relations, information layout, price and more. They are often facilitated directly when BIM authoring tools such as REVIT or Ecotect are used. BIM is not the same thing as $3 \mathrm{D}$ CAD. The fundamental purpose of $\mathrm{CAD}$ is to illustrate and help people visualize how buildings look, while BIM provides detailed information on how buildings work. Architects and civil engineers like BIM because it saves time in the design process, and builders and construction companies claim that it can also save money and time. BIM is best used when analysing how a whole group of complex variables functions together and it facilitates communication between the various parties involved in the design of structures making building design much easier. Since BIM increases the efficiency of the design process, it is a boom in sustainable design and architecture $[7,8]$.

\section{BIM management}

BIM management encompasses all IT processes in design based on the BIM system, including data storage, stakeholder collaboration, modelling, project design and printing finished documents. It is especially important to adapt the application to the regional standards and visual identity and standards of the company. In addition, a very important part of 3D modelling is the creation of 3D BIM elements according to the needs of the project, which can be very challenging for designers. BIM management can achieve the standardization of work processes, unification of operation and automation of work processes. Thus, it results in significant savings on the time required to produce documentation and reduces or almost eliminates the possibility of errors, particularly in calculating the amount and consistency of projects by different specialists.

When developing project documentation from a concept to detailed design, a range of different actions and protocols are used in order to obtain the final version. In many stages much more time is lost than is really needed. When total losses on an annual basis are added up, the figures are more than too much. For this reason, BIM addresses such issues as the introduction of standards and unification and automation of work processes.

This especially applies to the following aspects of work: storage data( directory structure, file structure, file 
nomenclature, versioning, data archives, data backup) and creating drawing templates (site plans, floor plans, sections, elevations, cladding, floor sections, water connections etc.

Due to the fact that BIM is used to build only one model, using predefined templates easily and quickly determines the type of display according to use.

\section{BIM technology in practice}

Architects and designers spend a great deal of time developing project documentation. It is more than 30 years since the introduction of information technology in design. Many things have changed and evolved in the meantime so that today's designers must be exceptionally computer literate. As technology progresses, it is increasingly difficult for them to follow the development of new technologies and trends. Builders have always made sketches and drawings that visually portray the objects to be built. Over time, these drawings have become more complex and detailed. As it developed, technology transformed 2D drawings into threedimensional models. There is no longer a need to draw lines to represent e.g. a wall; instead, a virtual wall is modelled, which can be shown graphically in the documentation (plan, section, elevation or 3D), or parametrically, to include other important in-formation (its purpose (load-bearing, non-load-bearing, partition), materials, layers, physical properties, life stage (existing, for demolition), and the like). Using tools for threedimensional design puts an emphasis on the process of design itself and facilitates the preparation of technical documents, while excluding possible errors in the early stage of the project (URL-5). The modelling procedure takes place in a few phases. In the early stages the basic building elements are modelled, such as walls, floors, ceilings and roof. Next, doors and windows, fences, and other details are modelled. As the final step, the surrounding terrain is modelled [1].

BIM management encompasses all IT processes in design based on the BIM system, including data storage, stakeholder collaboration, modelling, project design and printing finished documents. It is especially important to adapt the application to the regional standards and visual identity and standards of the company. In addition, a very important part of 3D modelling is the creation of 3D BIM elements according to the needs of the project, which can be very challenging for designers. Thus, it results in significant savings on the time required to produce documentation and reduces or almost eliminates the possibility of errors, particularly in calculating the amount and consistency of projects by different specialists. The bases of the system are parametric BIM 'intelligent' objects that are not only visual displays but also contain other information that is required in the process of design and preparation of technical documentation. Creating such elements is a very complex task because it must take into account many factors to meet the quality criterion. Consideration should be given to the visual representation relative to the type of display. The power of the BIM system is its continuous rigorous automatic monitoring of the quantity of materials and elements contained within the project. Interactive tables allow access to and control of all elements at all times. Quantity information is easily transferable to spreadsheets (Excel), which greatly facilitates the creation of price lists and other quantity statements. The form and parameters of tables are adapted to the needs of clients and local regulations and standards $[7,9]$.

\subsection{Use of BIM in static load analysis}

The BIM concept and its software allow various types of analyses of buildings and structures.

Besides allowing clear insight into the 3D structure of building and providing time and cost-related information, it also allows the making of a number of simulations for different analyses. What the computer produces as analysis and testing results is checked computationally to determine the reliability of the program by comparing the results.

Architects design using special architectural BIM software, construction engineers do their calculations using special construction BIM software, mechanical engineers do energy modelling using special mechanical engineering BIM software, thus, all engineers do their part of work on the same model, but each using their own specialized BIM software. In this way, a high degree of design reliability through various design phases is enabled. A static load analysis was carried out of the steel scaffolding designed in the UK by the Layher design studio. BIM software was a perfect medium between the design drawings and CAD models and analyses. Figs. 1 and 2 show the results of the analyses that are obtained by entering the values of the parameters of the structure.

Fig. 1 shows a diagram of cross-sectional forces, which clearly shows that the vertical rods are withstanding compression and the rods tension. Steel is the kind of material that better tolerates tension, while concrete can better withstand compression. It can be seen that the impact of forces is high around the roof ridge. The forces are the most negligible at the support points, increasing with the growing height of the structure.

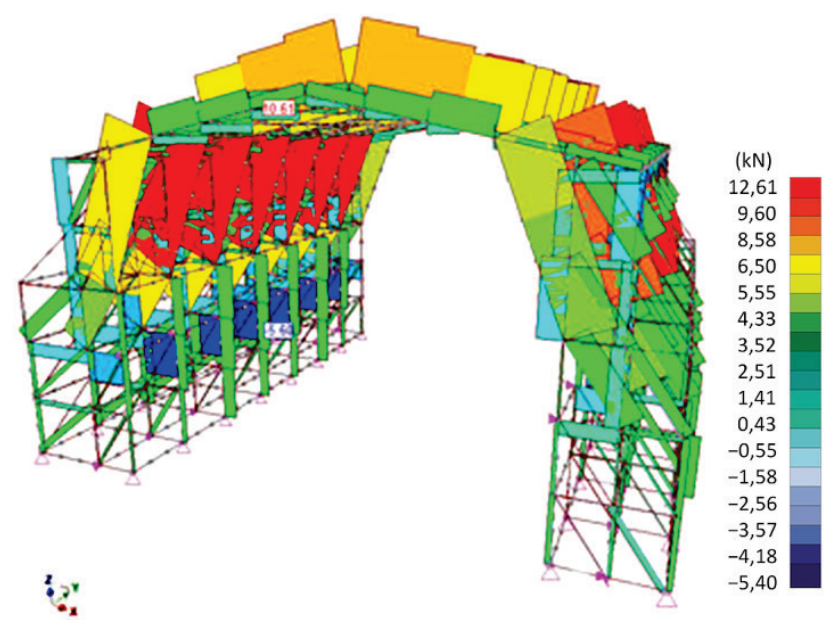

Figure 1 Diagram of cross sectional forces

In the upper parts the rods are also exposed to wind loading. According to the diagram shown in the figure (red), it is the slanted rods that take most of the loading because they are directly exposed to the impact of forces, transferring the load to the column rods. This simulation 
was made using BIM software to obtain the value of cross-sectional forces based on input parameters and values for the given structure.

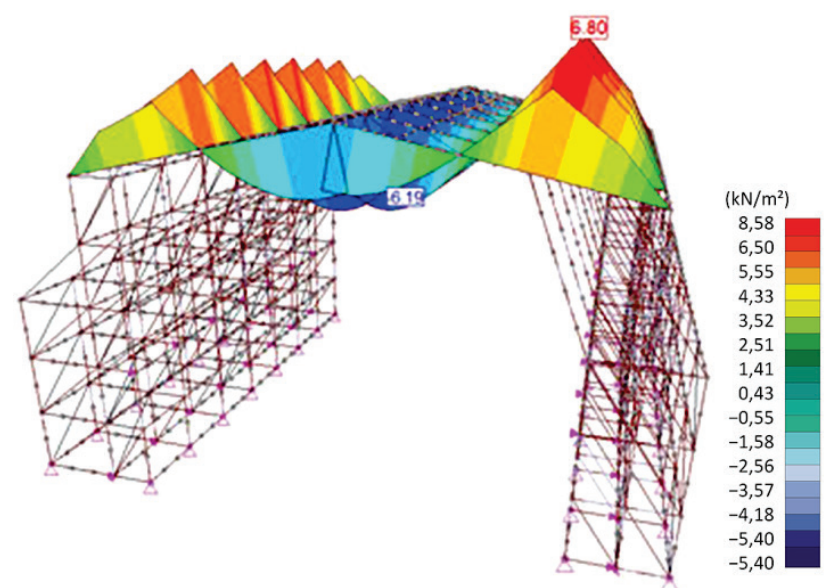

Figure 2 Diagram of tensile stress

Fig. 2 is a diagram showing the tensile loading of crossbeams. The red color shows compression, expressed as positive values $(+)$, which is also the highest compressive load equaling $6,80 \mathrm{kN} / \mathrm{m}^{2}$, while dark blue shows tensile loading, which is negative $(-)$, amounting to $-6,19 \mathrm{kN} / \mathrm{m}^{2}$ as the highest value. Tensile stress is evidently the highest in the area of the middle beams, i.e. the middle of the roof truss, while compressive stress is highest at the places where slanted rods support the beams. The rods were dimensioned taking into account the highest permitted stresses for the particular type of steel used, while making sure the structure was as light as possible to minimize the tensile loading along the ridge.

\section{Conclusion}

The advancement of information technology has also enabled the progress of technical science, which has used IT as a tool to solve its problems and issues. One such instance of ongoing advancement is the development of BIM technology, which has wide applications in practice. BIM technology, which was introduced to the AEC sector through the front door, promotes an interdisciplinary approach to the life cycle of a structure, including the design stage, building management and renovation or adaptive reuse. Since BIM management is at an early stage of development in most of Europe, the time is right to define the related work model and the role of experts.

The concept is such that allows collaboration and parallel data input by experts from various technical areas, which is then processed by the program to create a single database. Concrete examples of structures were presented to demonstrate the application of BIM software, which creates a clear picture by visualizing the static loading of the analysed building. The obtained values were used to dimension the elements of the structure, as dictated by the output parameters and load values.

The results of the analysis shown in Figs. 1 and 2 may be used to monitor structural loading and, if necessary, resize parts of the structure to ensure greater stability and safety. This is just one of many applications and possibilities provided by BIM software, which is of great importance in practice, particularly if simulations are carried out in the field using technology (tablets and other devices suitable for field work). This paper presents a methodology of creating BIM models, i.e. static load analysis. In conclusion, it may be said that BIM is highly applicable. BIM design is pretty simple as it allows the collection of variables and parameters, as well as their better visualization and presentation, which are certainly very important factors that positively impact the efficiency of BIM, especially when assessing the current state of a building. Naturally, the implementation of this type of methodology and tools requires considerable investment in hardware and software. Most of all, staff training must be a number one priority. They will learn how to work in a challenging software environment and thus be able to promote new approaches and business models.

\section{References}

[1] Bećirević, D.; Babić, L.; Cigrovski, I. Od podataka laserskog skeniranja do BIM modela postojećeg stanja. // Ekscentar. 17, (2004), pp. 87-92

[2] BIM - projektovanje po standardima savremenog građevinarsva.URL: http://www.buildmagazin.com/pdf/ build15.pdf

[3] Kelly. J.; Morledge. R.; Wilkinson. S.; Best value in construction. First ed. Oxford, UK, 2002.

[4] Eastman, C. M.; Fisher, D.; Lafue, G.; Lividini, J.; Stoker, D.; Yessios, C. An Outline of the Building Research Report. Institute of Physical Planning, Carnegie-Mellon University, Pittsburg, Research report No. 50, 1974.

[5] Autodesk 2003. Building Information Modeling. San Rafael, CA, Autodesk, Inc.

[6] URL: http://en.wikipedia.org/wiki/Building information modeling (January 2011)

[7] Grey, C.; Hughes, W. Building Design Management. Department of Construction Management and Engineering. University of Reading, UK, 2001.

[8] Sean, C. R. Applied Management Engineering. P. C. National Association of College and University, Boston, 2008 .

\section{Authors' address}

Tatjana Baroš, M.Sc. of architecture Faculty of Construction Management (Fakultet za graditeljski menadžment) University Union "Nikola Tesla" Beograd Cara Dušana 62-64, 11000 Beograd, Serbia E-mail: barostaca@gmail.com 